\title{
Pilonidal Sinus Excision: New Vision
}

\section{Mohamed Nada and Tamer M S Salama*}

Department of General Surgery, Ain Shams University, Egypt

\begin{abstract}
Background: Pilonidal sinus is chronic inflammatory condition that usually affects young adults, despite of the current advances in the field of medical research the best approach in managing Pilonidal sinus disease is not yet well defined. This study aims to evaluate a new technique for the excision of pilonidal sinus and investigates its effectiveness in terms of operation time, healing time, and the duration of hospitalization, the degree of postoperative complications and rate of recurrence
\end{abstract}

Methods: One hundred patients (93 males and 7 females) suffering from uncomplicated pilonidal sinus disease, underwent this new technique for pilonidal sinus excision. This technique based on lay open all visualized main and sides tracks of the sinus followed by excision of the whole area and closing underneath fascia and subcutaneous tissue

Results: The mean duration of intervention was 40 minutes and patients were discharged one day after the operation. The mean time for recovery and return to normal physical activity was 12 days (There were no intraoperative complications or mortalities in all cases).

Minor wound infection was the most common complication found as it occurred in 15 cases .Only 3 out of the 100 cases had recurrence. Finally, the overall patients satisfaction was more than $95 \%$.

Conclusion: From our experience, this technique possesses all the criteria for ideal pilonidal sinus surgery as it is associated with short hospital stay, fast wound healing, low recurrence rate and minimal complications.

Keywords: Pilonidal sinus; Surgery for pilonidal sinus; Complication of pinlonidal sinus

\section{Introduction}

Pilonidal sinus is chronic inflammatory condition that usually affects young adults and results from invasion of fallen hair into the skin. It mostly occurs in the natal cleft of the sacrococcygeal region and is presented by inflammation, abscess and sinus formation $[1,2]$. Despite of the current advances in the field of medical research,the best approach in managing Pilonidal sinus disease is not yet well defined. However, the treatment regimen should ideally minimize pain, allow short hospitalization time, reduce complications and rate of recurrence and should provide rapid recovery and return to normal daily activities [3]. There are several surgical procedures described for the treatment of pilonidal sinus disease including incision and drainage, excision and healing by second intention, which is currently the most commonly used procedure [4-6], excision and primary closure, excision with reconstructive flap techniques [7], however, the effectiveness of excision and primary closure in the treatment of pilonidal sinus disease is highly debated since it is associated with a high rate of recurrence. This can be due to the midline scar left from the procedure which further triggers the accumulation of loose hair, which is the original cause of pilonidal sinus formation $[5,6]$. Some less commonly used techniques such as phenol injection, cryosurgery and electrocautrization $[8,9]$. This study aims to evaluate a new technique for the excision of pilonidal sinus and investigates its effectiveness in terms of operation time, healing time, and the duration of hospitalization, the degree of postoperative complications and rate of recurrence.

\section{Patients and Methods}

One hundred patients (93 males and 7 females) suffering from uncomplicated pilonidal sinus disease with an age range of 18 to 50 years were enrolled in this study. Patients were admitted at the department of general surgery at El Demrdash Hospital at Ain Shams University in Cairo, Egypt from January 2013 to May 2015. An approval from the ethical committee of the Faculty of Medicine at Ain Shams
University was obtained to conduct this study. All patients were presented with chronic non-recurrent uncomplicated pilonidal sinus disease. The procedure was fully and clearly explained to patients who also provided an informed consent before operation. Patients were excluded from this study if any of the following was found: signs of pilonidal sinus disease complications such as abscess, osteomyelitis of the sacrum, fistula communicating with the rectum or anal canal, major medical co-morbidity diabetes or cardiac diseases. Furthermore, uncooperative or mentally ill patients were excluded. All patients were evaluated by clinical examination including digital rectal examination and a complete patient history was taken. Baseline investigations were performed to all patients including $\mathrm{CBC}$, blood urea/sugar, hepatitis, full chemistry and coagulation profile. Chest X-ray and ECG were done in patients who aged more than 40 years. An informed consent was taken from all patients. Intra-operatively, patients were put on the operating table in a prone position after taking spinal anesthesia. IV ceftriaxone was then given. For good exposure of the inter gluteal region, lateral traction from the lateral margin of the gluteus using adhesive tape was performed.

This technique is based on probing and lay open the main track and all visualized side tracks, which become visible to the naked eye after opening the main track, followed by gradual curettage to the whole raw area during which any pouting of granulation tissue represents an opening to side track, which was subsequently probed and lay

*Corresponding author: Dr. Tamer M Said, Lecturer of General Surgery Department of Surgery, Ain Shams University, 16 Foud Badwany Street Nasr City, Cairo, Egypt, Tel: 01113623458; E-mail: drtamer1981@hotmail.com

Received March 26, 2016; Accepted May 05, 2016; Published May 12, 2016

Citation: Nada M, Said TM (2016) Pilonidal Sinus Excision: New Vision. Surgery Curr Res 6: 274. doi:10.4172/2161-1076.1000274

Copyright: $\odot 2016$ Nada M, et al. This is an open-access article distributed under the terms of the Creative Commons Attribution License, which permits unrestricted use, distribution, and reproduction in any medium, provided the original author and source are credited. 
Page 2 of 3

opened. When no more opening for side tracks were detected, full excision around and just below the whole lay opened tracks was done guided by underneath healthy fat tissue, making sure that there is no more unhealthy granulation tissue or communicating tracks. Bilateral flaps including fascia were then elevated over the gluteus muscle not exceeding $2 \mathrm{~cm}$ to avoid ischemia. Then closure of the deep layer was started by an interrupted stitch using monocryl $2 / 0$ through the deep subcutaneous fat and fascia elevated on both sides together with the central fascia over the sacrum to decrease dead space. Finally, 2 or 3 stitches were taken to approximate the superficial subcutaneous fat, while the skin was left open. For hemostatic reasons, patients were nursed in the supine position. All Patients were discharged after one day of the operation and were followed-up once per week for 3 weeks and then after 3, 6 and 12 months from the operation. At each visit, wound examination was performed to assess healing and detect any development of complications.

\section{Results}

One hundred patients (93 males and 7 females) suffering from uncomplicated pilonidal sinus disease were enrolled in our study. The male to female ratio was 13:1 with a mean age of 37.6 years (ranged between 18 and 50 years).The most common presentation was purulent discharge from multiple openings (65\%), single opening (25\%) and history of swelling (drained abscess) followed with discharge (10\%) (Table 1). The mean duration of intervention was 40 minutes (ranged between 30 and 60 minutes) and patients were discharged one day after the operation. The mean time for recovery and return to normal physical activity was 12 days (ranged between 10 and 14 days). There were no intraoperative complications or mortalities in all cases. Minor wound infection was the most common complication found as it occurred in 15 cases (15\%). It was treated with antibiotic and frequent wound curettage during follow-up. Wound dehiscence in the superficial layer of the wound occurred in 5 cases only (5\%) and it was treated with antibiotic and daily wound dressing. Only 3 out of the 100 cases had recurrence. Postoperative pain was noticed in 10 cases and it only lasted for one week after the operation and responded well with analgesics (Table 2). In our study there was no occurrence of hematoma or seroma because the skin was left opened. However, one case had bleeding the next day after the surgery and it stopped with compression. Complete wound healing by secondary intention occurred after 23 day ranging from 18 to 27 days. Finally, the overall patient satisfaction was more than $95 \%$.

\section{Discussion}

Pilonidal disease is not considered a life-threatening condition. However, it can adversely affect patients' quality of life due to the associated pain, sinus discharge and some complications such as abscess formation [10]. This disease can be treated with two distinct surgical methods comprising open and closed methods. The open method includes leaving the residual cavity opened after sinus excision, whilst the closed method includes closure of the residual cavity after sinus excision [11]. The open method is easy to perform and is associated with low recurrence rate. However, its main disadvantages can be concluded in the slow wound healing and the requirement of daily wound care [12]. In the closed methods, there are different types of wound closure, including midline closure, an off-midline closure or a flap reconstruction. However, none of these techniques are considered optimum in the treatment of pilonidal sinus disease [13].

In this study, the mean time for post operative hospital stay and the mean time required for complete wound healing associated with

\begin{tabular}{|c|c|c|c|}
\hline \multirow{2}{*}{ Gender N (\%) } & Male & 93 & $93 \%$ \\
\hline & Female & 7 & $7 \%$ \\
\hline Ratio & & \multicolumn{2}{|c|}{$13: 1$} \\
\hline \multirow{2}{*}{ Age } & Range & 18 & 50 \\
\hline & Mean \pm SD & 37.620 & 11.578 \\
\hline \multirow{3}{*}{$\begin{array}{c}\text { Most common } \\
\text { presentation } \mathrm{N}(\%)\end{array}$} & $\begin{array}{c}\text { purulent discharge from multiple } \\
\text { opening }\end{array}$ & 65 & $65 \%$ \\
\hline & single opening & 25 & $25 \%$ \\
\hline & $\begin{array}{l}\text { History of swelling (drained abscess) } \\
\text { followed with discharge }\end{array}$ & 10 & $10 \%$ \\
\hline \multirow{2}{*}{$\begin{array}{l}\text { Duration of } \\
\text { intervention }\end{array}$} & Range & $30 \mathrm{~min}$ & $60 \mathrm{~min}$ \\
\hline & Mean \pm SD & $40 \mathrm{~min}$ & 8.936 \\
\hline \multirow{2}{*}{$\begin{array}{l}\text { Recovery time to } \\
\text { normal physical } \\
\text { activity }\end{array}$} & Range & 10 day & 14 day \\
\hline & Mean \pm SD & 12 & 1.421 \\
\hline \multirow{2}{*}{$\begin{array}{l}\text { Complete Wound } \\
\text { healing by } \\
\text { secondary intention } \\
\text { occurs after }\end{array}$} & Range & 18 day & 27 day \\
\hline & Mean \pm SD & 23 & 3.318 \\
\hline
\end{tabular}

Table 1: Shows demographic, preoperative and operative data of the patients.

\begin{tabular}{|c|c|c|}
\hline Postoperative complications & N & \% \\
\hline Minor wound infection & 15 & 15 \\
\hline wound dehiscence occurs in 5 cases & 5 & 5 \\
\hline recurrence & 3 & 3 \\
\hline Hematoma & 0 & 0 \\
\hline Seroma & 0 & 0 \\
\hline
\end{tabular}

Table 2: Shows incidence of postoperative complications of this technique.

our technique were investigated since they are considered the main indicators for successful treatment. We found that the mean post operative hospital stay was only one day, while the mean time required for complete wound healing was about three weeks. These durations are comparable to that of the closed procedure and are far less than that of the open technique. In a study performed by Zahid et al. [14], they found that the average hospital stay for wide open excision method was 5.6 days and for Karydakis procedure (a closed technique) was 2.5 days. Moreover, they found that complete wound healing occurred after 7.5 weeks in cases with open excision, while in karydakis cases complete wound healing occurred after 3 weeks. Another study [15] stated that complete wound healing occurs at 6-12 weeks after open excision and at 10-16 days after closed excision. From our experience, the incidence of minor wound infection in our technique was $15 \%$, while according to the literature; the incidence of wound infection in wide open excision of pilonidal sinus disease was reported to be 1.8 to $30 \%$ and it was between $3.8 \%$ and $14 \%$ with Karydakis procedure [16,17].

In a study conducted by Zahid et al. [14], 75\% of patients had experienced postoperative pain after wide open excision, while $25 \%$ of patients had experienced postoperative pain following Karydakis procedure. Similar results were obtained in another study [18], where mild to moderate postoperative pain had occurred after closed pns excision technique and disappeared after 2 weeks, while in case of wide open excision the pain was moderate to severe and it took almost 5-7 weeks to resolve. In our study, postoperative pain was mild to moderate and it resolved in duration closely comparable to pain that occurs after excision with closure technique where it didn't exceed one week and responded well to analgesics. In this study, recurrence occurred in only three cases with an incidence rate of $3 \%$. This low rate of recurrence may be due to allowing wound healing by secondary intention. This 
rate of recurrence is much lower than rate of recurrence associated with excision and closed techniques and very similar to rate of recurrence associated with excision and open technique. This was also supported by results of other studies $[18,19]$, in which the recurrence rate after wide open excision was reported to be $0.6 \%$ and $5 \%$, while in cases of wound closure after excision, it was $3.5 \%$ and $42 \%$. In this study, there was no seroma or hematomas in contrast another study [18] sates that this complication is common after wound closure in pns surgeries procedures $[18,19]$.

In this study, we found that our technique has combined the benefits of wound closure procedure which has fast wound healing and short hospital stay with minimal complications with the benefits of open wound excision procedures which are associated with low recurrence rate and absence of seroma and hematoma. Moreover, it has an overall patients' satisfaction of more than $95 \%$.

\section{Conclusion}

From our experience, this technique possesses all the criteria for ideal pilonidal sinus surgery as it is associated with short hospital stay, fast wound healing, low recurrence rate and minimal complications.

\section{Conflict of Interest}

No any type of financial support, the authors report no conflicts of interest.

\section{References}

1. Bertelsen CA (2011) Cleft-lift operation for pilonidal sinuses under tumescent local anesthesia: a prospective cohort study of peri- and postoperative pain. Dis Colon Rectum 54: 895-900

2. Surrell JA (1994) Pilonidal disease. Surgical Clinics of North America 74: 13091315.

3. Karaca AS, Ali R, Capar M, Karaca S (2013) Comparison of Limberg flap and excision and primary closure of pilonidal sinus disease, in terms of quality of life and complications. J Korean Surg Soc 85: 236-239.

4. Miller D, Harding K (2003) Pilonidal sinus disease.
5. Chintapatla S, Safarani N, Kumar S, Haboubi N (2003) Sacrococ-cygeal Pilonidal sinus: Historical review, pathologi-cal insight and surgical options. Tech Coloproctol 7: 3-8.

6. Lee HC, Ho YH, Seow CF, Eu KW, Nyam D (2000) Pilonidal disease in Singapore: Clinical features and management. Aus NZ J Surg 70: 196-198.

7. Müller K, Marti L, Tarantino I, Jayne DG, Wolff K, et al. (2011) Prospective analysis of cosmesis, morbidity, and patient satisfaction following Limberg flap for the treatment of sacrococcygeal pilonidal sinus. Dis Colon Rectum 54: 487494.

8. Duchateau J, De Mol J, Bostoen H, Allegret W (1985) Pilonidal sinus excision marsupialization - phenolization? Acta Chir Belg 85: 325-328.

9. Shafik A (1996) Electrocauterization in the treatment of pilonidal sinus. Int Surg 81: 83-84.

10. Lorant T, Ribbe I, Mahteme H, Gustafsson UM, Graf W (2011) Sinus excision and primary closure versus laying open in pilonidal disease: a prospective randomized trial. Dis Colon Rectum 54: 300-305.

11. Gencosmanoglu R, Inceoglu R (2005) Modified lay-open (incision, curettage, partial lateral wall excision and marsupialization) versus total excision with primary closure in the treatment of chronic sacrococcygeal pilonidal sinus: a prospective, ran domized clinical trial with a complete two-year follow-up. Int J Colorectal Dis 20: 415-422.

12. Soll C, Hahnloser D, Dindo D, Clavien PA, Hetzer F (2008) A novel approach for treatment of sacrococcygeal pilonidal sinus: less is more. Int $\mathrm{J}$ Colorectal Dis 23: $177-180$.

13. Yoldas T, Karaca C, Unalp O, Uguz A, Caliskan C, et al. (2013) Recurrent Pilonidal Sinus: Lay Open or Flap Closure, Does It Differ?. Int Surg 98: 319323.

14. Aman Z, Hadi A, Ahmad T, Khan AS, Shah OF, et al. (2011) Comparison of Wide Open Excision and Karydakis Procedure for Pilonidal Sinus Disease. Journal of Surgery Pakistan (International) 16: 136-139.

15. Mohammed A (2007) Karydakis flap operation for chronic pilonidal sinus Pakistan journal of surgery 23: 65-69.

16. Amir M, Raja MH, Klaye TO (1999) Surgical treatment of chronic pilonidal sinusopen versus closed excision. J Coll Physicians Surg Pakistan 9: 518-521.

17. Spivak H, Brook VL, Nussbaum M, Friedman I (1996) Treatment of chronic pilonidal disease. Dis colon rectum 39: 1136-1139.

18. Al Jaberi TM (2001) Excision and simple primary closure of chronic pilonidal sinus. Eur J Surg 167: 133-135.

19. Chiedozi LC, Al-Rayyes FA, Salem MM, Al-Hadi FH, Al-Bidewi AA (2002) Management of Pilonidal dis-ease. Saudi Med J 23: 786-788. 